\title{
The State Botanical Garden of Georgia: A Living Laboratory for Student Education
}

\author{
A.J. Lewis and J.M . Affolter ${ }^{2}$
}

ADDITIONAL INDEX WORDS. field trips, independent study, undergraduate research/ education, graduate research, internships, work-study, arboreta

Summary. The State Botanical G arden of G eorgia serves as an important academic resource for the $\mathbf{U}$ niversity of $\mathbf{G}$ eorgia by supporting interdisciplinary learning experiences in fields including botany, horticulture, environmental design, ecology, anthropology, geography, instructional technology, science education, entomology, forestry, and art. Field trips, independent study, internships, work-study and other botanical garden experiences strengthen and support the university's teaching, research and public service/ outreach missions.

ollege and university affiliated botanical gardens can serve significant roles in both undergraduate and graduate education. The State Botanical G arden of Georgia (SBGG) has established numerous collaborations with academic departments on campus in an effort to enhance its value as an educational resource within the $U$ niversity of Georgia (U GA).

SBGG provides students in horticulture and botany an opportunity to see plants in context with the natural environment as well as designed landscapes. Field trips, independent study, undergraduate and graduate research opportunities abound, ranging from taxonomic surveys and plant systematics to plant conservation projects (Fig. 1). For example, both undergraduate and graduate students have been involved in our plant conservation program on a variety of levels, from conducting simple propagation experiments for research and public display purposes to more sophisticated studies determining genetic diversity in rare plant populations.

In addition to horticulture and botany, SBG G serves as a base for student projects in environmental design and ecology. O ur garden frequently serves as the site for design projects that originate from both classes and individual assignments. We work as clients with teachers, major professors and students to make the projects real and to ensure that they relate as much as possible to our master plan.

The cost of publishing this paper was defrayed in part by the payment of page charges. U nder postal regulation, this paper therefore must be hereby marked advertisement solely to indicate this fact.

${ }^{1}$ D irector, State Botanical Garden of Georgia, 2450 S. M illedge Ave., Athens, GA 30605, and professor of horticulture, U niversity of Georgia.

${ }^{2}$ D irector of research, State Botanical Garden of G eorgia, and associate professor of horticulture, U niversity of Georgia. 
Recent studies have included renovation and expansion of our $\mathrm{Na}$ tive Flora Garden and a conceptual plan for aJ apanese garden. Whilethese projects seldom yield designs that can beimplemented verbatim, they do provide good ideas for refinement and presentation to prospectivedonorsat a later date, e.g., conceptual plans for the $\mathrm{H}$ eritage Garden, now funded and slated for construction. $O$ ur garden is presently serving asatest sitefor form $\cdot Z$ (auto dessys, inc., Columbus, O hio) a three dimensional modeling software package being integrated into the UGA School of Environmental D esign's teaching curriculum.

While graduate students in ecology have used our garden for various research projects, undergraduate students are being introduced via an innovative project funded by the $\mathrm{Na}$ tional Science Foundation's Division of U ndergraduate E ducation. Project RELATE (Realizing Environmental Literacy through Advanced Technology and Experimentation) was developed in collaboration with faculty in the departments of Geography and Instructional Technology. The purpose of the project is to involve undergraduate students in two long-term ecological research studies that take place in the garden's natural areas.

The RELATE Forest $L a b$ examines the effect of past land-use (agricultural practices) on secondary succession. Students compare tree species (composition and biomass) in two forest plots, one that developed in the absence of topsoil and one that developed on intact topsoil. In the Stream $\mathrm{Lab}, \quad$ students sample macroinvertebrates from a stream bed and calculatea bioindex of stream quality based on the presence of tolerant, somewhat sensitive, and sensitive taxa (Fig. 2).

A primary goal of Project RELATE hasbeen to develop multimedia software to prepare students for field work at the garden and to assist them in analyzing their data. The software enablesstudents to construct, explore, and visualize their data sets in a creative fashion. Project RELATE also utilizes ArcView software (Environmental Systems Research Institute, Inc., Redlands, Calif.) to introduce students enrolled in an undergraduate geography course to computerized geographic information systems (GIS). U sing a GIS database depicting the topography, soils, and natural vegetation of the garden's 313 acres (126 ha), students formulate and compare alternative scenarios for future site development at SBGG.

The development team for Project RELATE included graduate students in the departments of Instructional Technology, Geography, E cology, and $\mathrm{H}$ orticulture. In addition to supporting their studies by providing research assistantships, the project has become an important component of the research theses and portfolios of several of the students. M ore information on Project RELATE is available on the Internet (Environmental Research Support Site, 1997; Project RELATE, 1997).

Other disciplines which SBGG serves are anthropology and ethnobotany. For several years, students in anthropology haveplanted and tended a native American garden using cultural methods and techniques appropriate to the period. Projects such as this often provide a good basis on which to build general public education programs, e.g., Early A merica asa Garden, an interdisciplinary lecture series cosponsored by the U GA H istory D epartment exploring themes in American history and ethnoculture.

The Garden is currently cooperating with UGA's Center for Latin American and Caribbean Studies to develop a Latin American Ethnobotanical $G$ arden on the U GA campus, adjacent to the building that housesthedepartment of Anthropology. Thiscollection incorporates wild-collected plant species from sites in M exico, Argentina, CostaRica, and other Latin American countries where UGA faculty and students are conducting research concerning the indigenous use, production, and conservation of medicinal plants. In addition to assisting in the design of the garden and propagation of plant material, SBGG is also providing expertise in collectionsmanagement and interpretation (Fig. 3).

Because of its high profile location on campus and the emergence of UGA as a center for ethnomedical studies, the Latin American Ethnobotanical $G$ arden isan important resource for education and research as well as an attractive display garden for the public. The SBG G D irector of R esearch is a collaborator in a newly funded $\$ 2.5$ million grant from three federal agencies that will explore biodiversity and chemical properties of $M$ ayan medicinal plants in the Mexican state of Chiapas. $M$ any of these species will be included in collections at SBGG and on campus.

Science education is another area
Fig. 1. An ecology student earns graduate credits by assisting State B otanical $\mathbf{G}$ arden of $\mathbf{G}$ eorgia staff in research concerning the pollination of Indian Pink (Spigelia marilandica L.) (photo by H. Nourse).

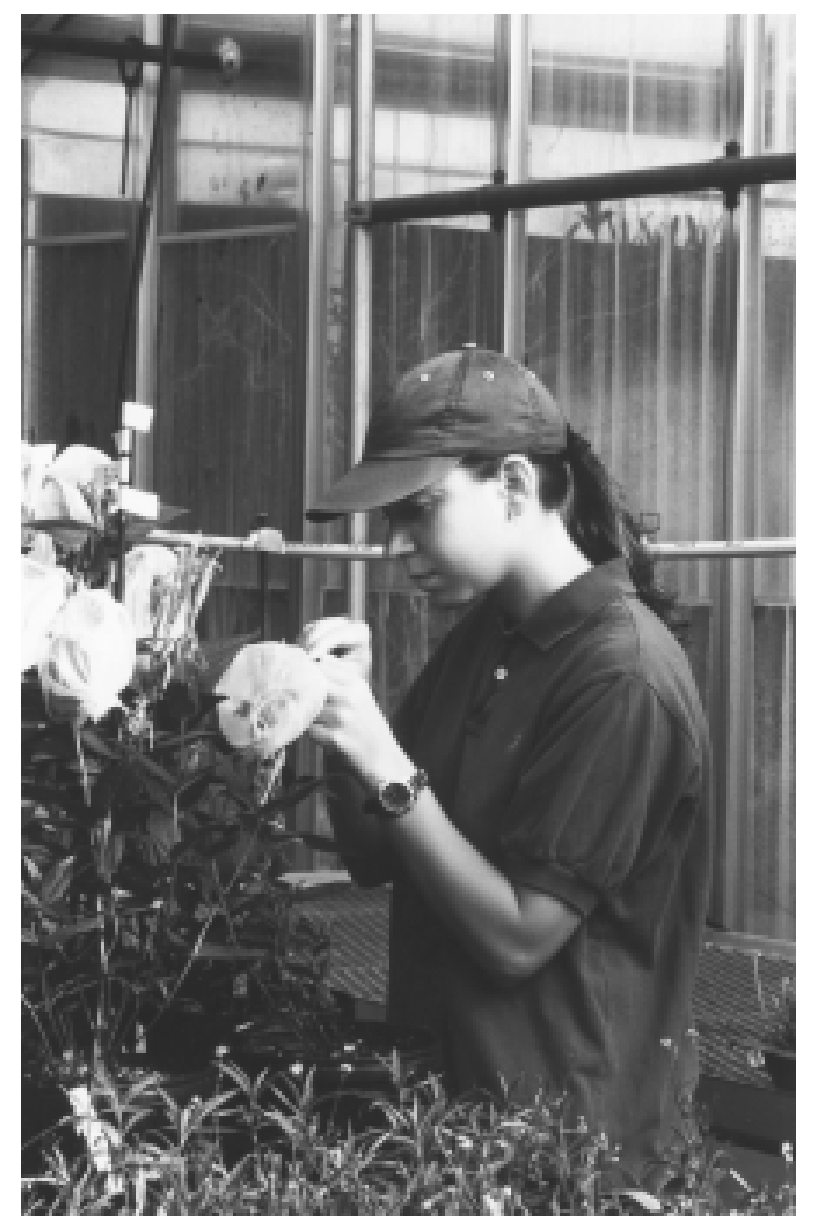

Hortlechnology • O ctober-D ecember 1999 9(4) 


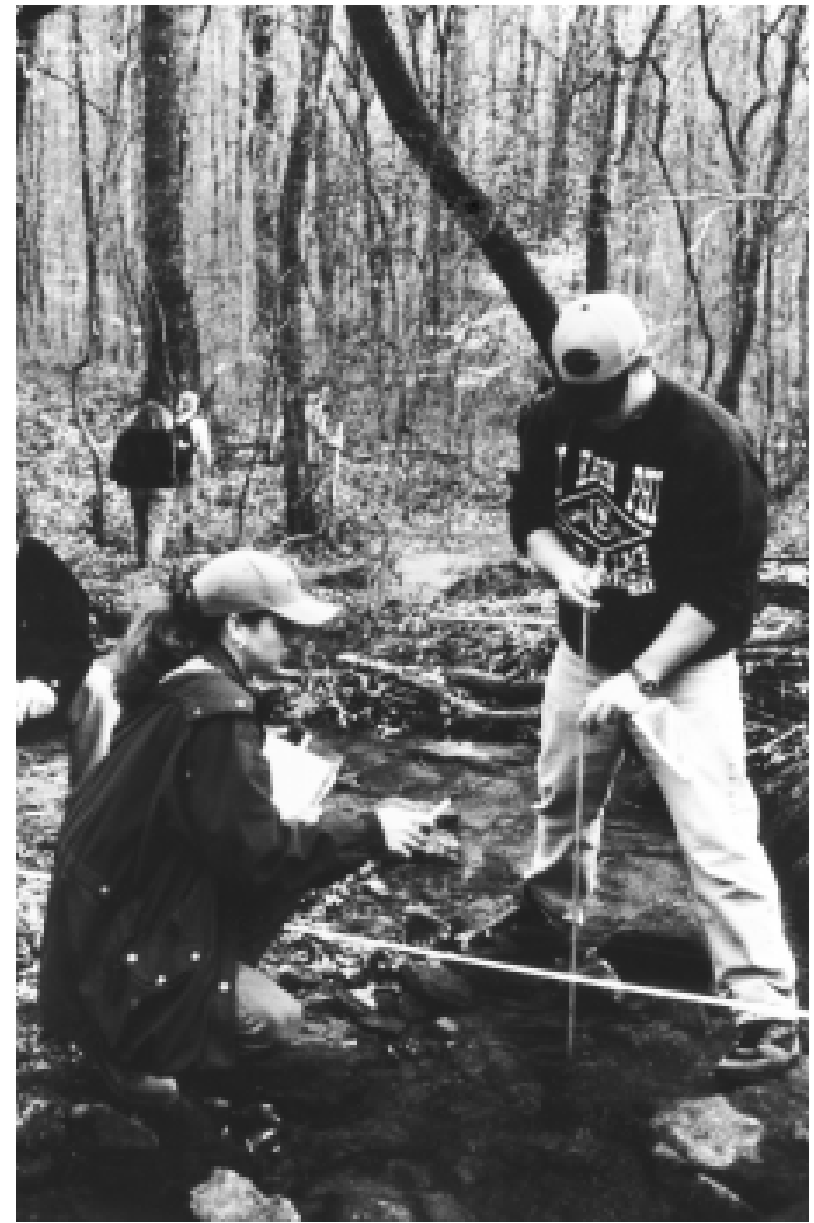

Fig. 2. As part of Project RELATE, undergraduate students in an environmental literacy course measure the cross-section of a stream in one of the State B otanical G arden of G eorgia's natural areas (photo by J. Affolter).

in which SBGG plays a vital role. We have offered several teacher training workshops in environmental education using our native plant collections [e.g., pitcherplant (Sarracenia L.) bog] as resources. A new program begun in 1996 and cosponsored by the Georgia Plant Conservation Alliance is the Georgia Endangered Plant Stewardship N etwork. Through this network, students across the state are learning about and actually growing endangered plant species. For schools to participate, teachers must first attend a

Fig. 3. As part of his research assistantship, a horticulture graduate student propagates plants collected in C hiapas, M exico, for addition to the L atin American Ethnobotanical $\mathbf{G}$ arden at the $\mathbf{U}$ niversity of $\mathbf{G}$ eorgia (photo by H. N ourse). workshop preparing them to teach about endangered plants and related science inquiry activities. T eachers receive continuing support through a web site (Georgia Endangered Plant Stewardship N etwork, 1999), listserve and newsletter. Programsabout plant conservation have also been offered off-sitevia Georgia's distance learning network, GSAM S.

SBG G supportfor undergraduate and graduate education is by no meanslimited to the few disciplines mentioned. Entomology students are involved in several of our recurring programs, notably Insectival, which introduces children and adults to the fascinating world of insects. Students create displays, answer questions, and handle live insects. Forestry students in dendrology use the garden as a site for field trips. Art students frequently use the garden as subject matter and have exhibited their work indoors and outdoors.

In addition to a formal internship program, wealso offer venuesfor work- scholarships provided by The $\mathrm{G}$ arden Club of Georgia as well as opportunitiesfor U GA students to learn on-thejob. These opportunities go beyond horticulture and gardening; students work in conservation biology, public relations, special events, plant records, educational programs, and other areas. T wo recent international students have further broadened this experience.

In summary, SBG G offersabroad platform for students in many disciplines to explore diverse topics within a highly relevant and holistic context, a living laboratory. While SBG G justifiably serves as a public display garden and local cultural amenity, more importantly it underpins and supports the academic experience of countless students at UGA and beyond. More information about SB G G can befound on the Internet (The State Botanical Garden of Georgia, 1997.)

\section{Literature cited}

Environmental Research Support Site. 1997. U niversity of G eorgia. 20 Sept. 1998. <http:/ / Ipsl.coe.uga.edu/ projects/ ERSS/ home.html>.

Georgia Endangered Plant Stewardship $\mathrm{N}$ etwork. G eorgia Plant Conservation Alliance. 1999. 20 Sept. 1998. <http:/ / www.uga.edu/ botgarden/ GEPSN .html>

Project RELATE. U niversity of Georgia. 1997. <http:/ / Ipsl.coe.uga.edu/ RE LATE/ Envirolit.html>

The State Botanical Garden of Georgia. 1997. <http:/ / www.uga.edu.botgarden. html>

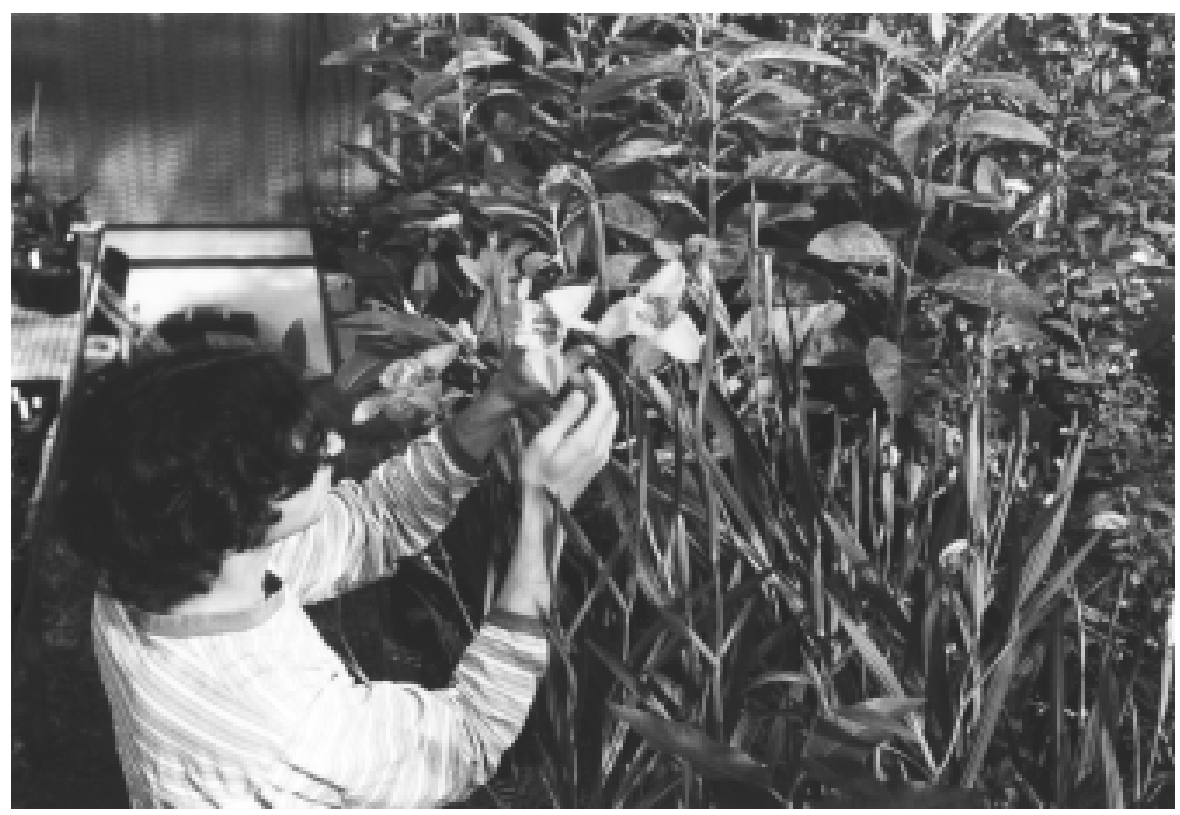

